\title{
Erratum: The role of physiotherapy in the respiratory management of children with neuromuscular diseases: A South African perspective
}

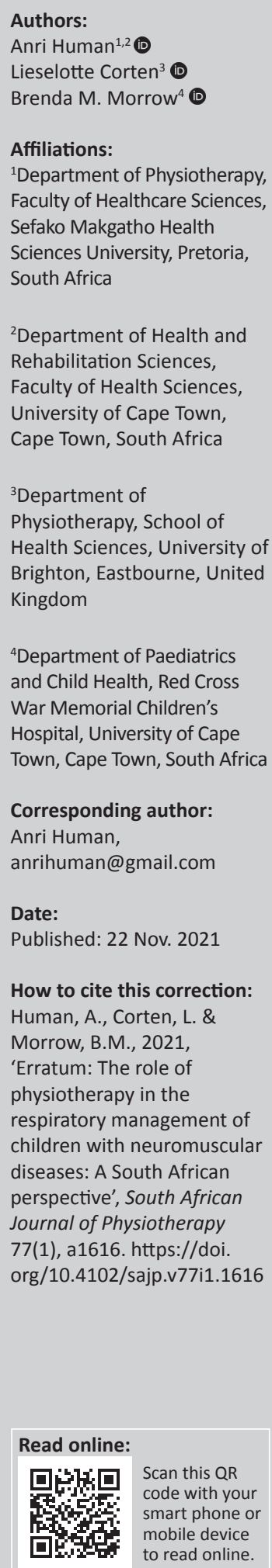

Copyright: (c) 2021. The Authors. Licensee: AOSIS. This work is licensed under the Creative Commons Attribution License. Note: DOI link to the original article: https://doi.org/10.4102/sajp.v77i1.1527
In the version of the article initially published, Human, A., Corten, L. \& Morrow, B.M., 2021, 'The role of physiotherapy in the respiratory management of children with neuromuscular diseases: A South African perspective', South African Journal of Physiotherapy 77(1), a1527. https://doi. org/10.4102/sajp.v77i1.1527, the publication year was given incorrectly. The correct publication date should be 07 May 2021 instead of 07 May 2020 in the 'Dates' section.

This correction does not alter the study's findings of significance or overall interpretation of the study's results. The publisher apologises for any inconvenience caused. 